\title{
Performance assessment of an improved cook stove (Esperanza) in a typical domestic setting: implications for energy saving
}

Mapereka Francis Chagunda ${ }^{1 *}$, Caspah Kamunda ${ }^{1}$, Justice Mlatho ${ }^{2}$, Chomora Mikeka ${ }^{2}$ and Lobina Palamuleni ${ }^{1}$

\begin{abstract}
Background: Much of the Malawi's energy source, which is biomass, is consumed using traditional household technologies. These technologies contribute to over consumption of biomass leading to increased forest degradation, and they release various gases and particulate matter that often cause indoor air pollution which is a health hazard to the users. To combat deforestation and pollution, improved cookstoves were introduced in Malawi from early 2000. A number of improved stoves were introduced including Esperanza which is reported to have 60\% wood fuel saving under controlled conditions compared to the traditional 3-stone stove. The efficiencies of improved stoves were obtained through controlled cooking test, but very limited studies have evaluated them under normal household settings. Therefore, this study sought to compare the performance of the Esperanza stove with a 3-stone stove in a typical domestic setting.

Methods: A Volunteer in Technical Assistance (VITA) standardized questionnaire was administered to households that were using the Esperanza stove. A cross-sectional Kitchen Performance Test (KPT) was conducted to compare the wood-saving performance of exclusive use of Esperanza stove and the 3-stone stove using the VITA KPT tool.

Results: In the study area, a policy of banning household use of other cooking technologies has been in place with the main goal of encouraging the use of new technologies. There is evidence that the Esperanza stove was used more often, though it was used in combination with other technologies. Although Esperanza stove had earlier been reported to be more fuel efficient than the 3-stone stove, results revealed that due to improper use, the Esperanza stove consumed $86 \%$ more wood fuel compared to 3-stone stove.

Conclusions: Three-stone stoves are still the preferred mode of cooking technology in most rural and peri-urban environments in Malawi. The shift to the improved stove technologies therefore requires urgent government intervention to ensure total use of these technologies that save energy and the environment. Additionally, the optimum efficiency of the Esperanza stove can be viable with training to new users. Thus, the importance of training on the proper use of Esperanza stove is recommended in order to optimize its performance and maximize energy saving.
\end{abstract}

Keywords: Biomass, Wood fuel, Esperanza stove, Malawi

\footnotetext{
* Correspondence: mapchagunda@gmail.com

${ }^{1}$ North-West University, Mafikeng Campus, Mahikeng, North West Province,

South Africa

Full list of author information is available at the end of the article
} 


\section{Background}

It is estimated that around two-thirds of the population in developing countries rely on biomass fuel (wood, dung, and fiber residues) for cooking and heating [1]. Malawi is a developing country with $84 \%$ of 2.3 million households living in rural areas where biomass supplies about $99 \%$ of household energy demand. The household sector is the most dominant energy consumer, accounting for about $84 \%$ of total energy consumption in Malawi [2]. An estimated $48 \%$ of wood fuel is from sustainable yield while $47 \%$ is taken from natural woodlands that are quickly varnishing without replacement. The remaining 5\% comes from other biomass sources that include crop and industrial residues [2].

Most of Malawi's biomass energy source is consumed in traditional end-use technologies, whose efficiencies are low; around 10-12\% [2]. High dependency on the use of technologies that have relatively low conversion rate of biomass to energy is one of the factors that is contributing to the overconsumption of biomass. Thus, traditional cookstoves (specifically the 3 -stone stove) use more biomass that leads to increased rate of forest degradation [3]. Moreover, these inefficient stoves release various gases and particulate matter that often cause indoor air pollution, leading to potential health hazard to the users [4].

Research on improved technologies for energy conservation in developing countries is a continuous process which has resulted in the design of several types of improved cookstoves for use by rural households [5]. Compared to a basic 3-stone stove with 10-15\% thermal efficiency, improved cooking stoves can easily halve the fuel requirements of the cooking process [4]. However, before any stove is introduced on the market, it is first evaluated for its efficiency and usability against set international standards [5]. These tests provide reliable information about stove performance that informs the stoves committee on how to select a locally appropriate and energy-efficient stove for each cooking task.

The Program for Biomass and Energy Conservation (ProBEC) which implements biomass energy technology (BET) interventions in Malawi, Zambia, and Tanzania has introduced several types of improved cook stoves. Some of these improved biomass stoves constitute a closed fire technology with a mechanism in which the user voluntarily distributes and controls the heat (Fig. 1).

The improved biomass stove has helped millions of people who rely on low-cost, readily available biomass fuels who cannot afford more expensive modern stoves and fuels [6]. A number of improved stoves have been introduced in several parts of Malawi [7], including the Changu stove, Metal Rocket stove, Esperanza stove, Chitetezo mbaula, and Briquette stoves. Figure 2 shows these different types of improved stoves alongside the traditional 3-stone stove.

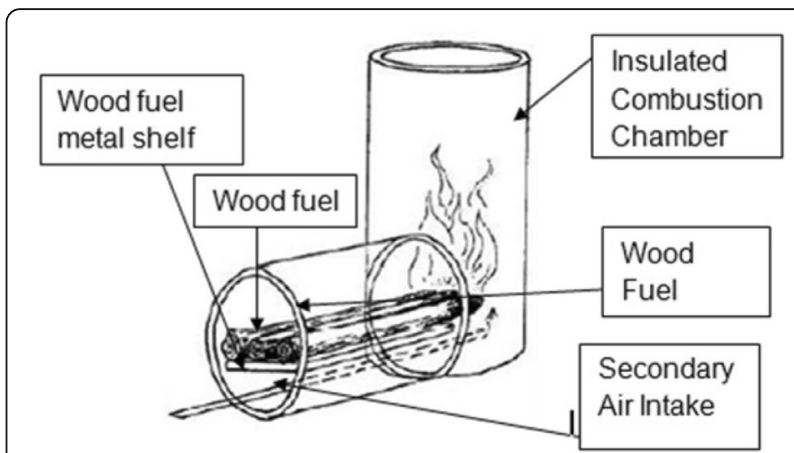

Fig. 1 Conceptual diagram of the improved stove

The key principle behind these stoves is to reduce biomass consumption for each cooking task by improving efficiency [5]. Thus, information on energy saving of these stoves help organizations to make informed decisions on which stoves to adopt compared to others in order to save more wood fuel. In addition, provided that sufficient training is given, the potential wood fuel saving of the improved stoves could negate the reported energy saving and fuel efficiency.

The Esperanza stove was introduced in the Phalombe and Mulanje districts as part of an intervention to preserve the fast degrading environment around Mulanje Mountain. In 2006, it was reported that in Mulanje alone, the total energy consumption was estimated to be 3.12 million GJ; out of which, $97.5 \%$ was biomass energy [8]. To get maximum efficiency from the Esperanza stove, specific rules need to be disseminated through training to the potential users and the stove user guide. This training is on how to operate the stove before starting it and during its use. Users are encouraged to consult and follow instructions in the stove user guide to ensure maximum energy saving and fuel efficiency. The instructions include removing ash each time before starting fire to prevent the ash from choking the stove. The ash hole has to always be kept closed on the outside of the stove when cooking to prevent entrance of cold air into the combustion chamber and escaping of heat from the combustion chamber. When cooking, it is important to ensure that the wood fuel is not burning outside the stove fire entrance. Also, the use of pots that do not leave big gap around the pot skirt of the stove are recommended to increase the transfer of heat to the cooking pot thereby preventing wastage of generated heat, which consequently could reduce the efficiency and wood-saving aspects of the stove.

Studies have shown that there is over dependence on wood fuel and charcoal sources in Mulanje and Phalombe. To address the problem, GTZ-ProBEC designed various types of improved cooking stoves. The performances of 


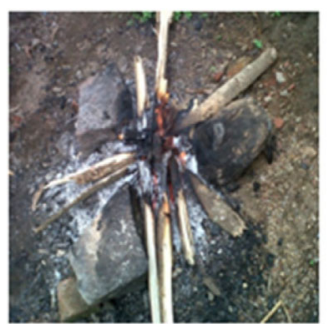

3 -stone stove

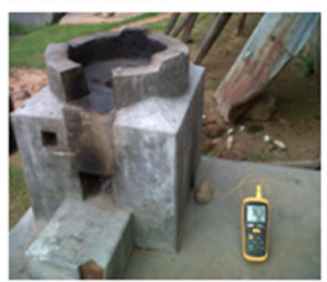

Esperanza stove

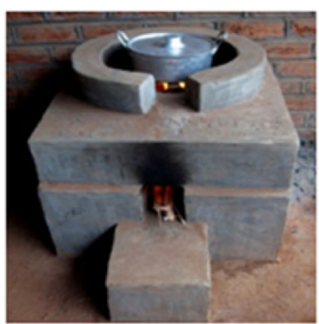

Changu stove

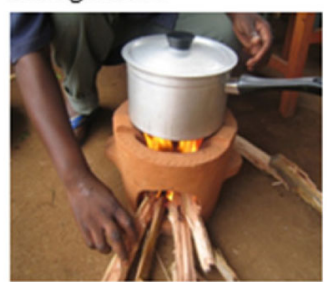

Chitetezo mbaula

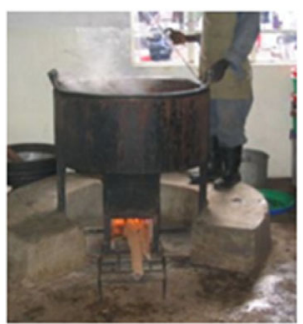

Metal Rocket stove

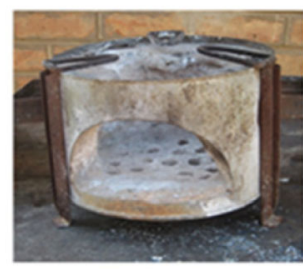

Briquette stove

Fig. 2 Three-stone stove and selected improved stoves

these improved stoves had initially been assessed in the laboratory, through controlled cooking tests (CCTs) [9], and were found to be higher than that of the 3-stone stove. Laboratory testing provides a cost-effective means of evaluating cookstoves while controlling variables that are difficult or impossible to control in the field. Despite such advantages, controlled laboratory testing cannot fully duplicate field testing but should emulate field conditions to the greatest extent possible. Although, this had been the case, very few studies have evaluated these improved stoves under normal household conditions [10]. Thus, it is important to investigate the performance of improved stoves under household conditions as efficiencies could differ from the CCT results as it was observed with plancha stove in Guatemala. For example, in standard water boiling and cooking tests, the plancha consumed more fuel and took longer than the open fire, but in 5-day tests of routine cooking, the plancha was found to use $39 \%$ less wood fuel than that of the open fire [11]. Therefore, the objective of this study was to assess the performance of the Esperanza stove in a typical domestic setting.

This paper begins with an introduction to the sources of energy and the traditional technologies that are used and their impacts on the environment and health. It discusses improved technologies that are meant to address the problems that are caused by the traditional technologies. The Esperanza stove is an example of improved technology and this study compares the performance of the improved technology with the traditional 3-stone stove. The analysis is based on the usage and consumption of wood fuel in estimating variations in wood fuel savings. The last section provides the conclusion and recommendations for future research studies.

\section{Description of the study area}

Mulanje is in the Southern region of Malawi located at $15.9346^{\circ} \mathrm{S}$ and $35.5220^{\circ} \mathrm{E}$. It has a population of 525,429 [12] covering an area of $3309 \mathrm{~km}^{2}$. Mulanje is where the third highest mountain in Africa is found. The mountain is a tourist attraction entity for the country because of its unique environment. It has big tea estates surrounding it. The estates employ many people surrounding it who can harm the unique environment if not controlled on their wood fuel usage. The employed workforce by Eastern Produce Malawi (EPM) fluctuates between 7500 and 15,000 employees (GTZ-ProBEC: Rocket stoves and other technologies in Malawi, unpublished). EPM has a group of tea estates, one of which is the Eldorado Tea Estate. There are two compounds in the Eldorado Tea Estate that are close to each other in which one compound uses 3-stone stoves (they do not have Esperanza stoves in their kitchens) and the other has Esperanza stoves in its kitchens. Figure 3 shows map of the study area.

\section{Methods}

In this study, the Esperanza stoves are fixed in kitchens of tea estate houses used by the estate workers. The workers do not pay for the stoves as it was a policy of the Eldorado Tea Estate that every house has to be fitted and use an Esperanza stove. It is required that every household that has Esperanza stove in its kitchen should be trained on how to use it and a user guide was left with them. When the stoves are installed in the kitchens, all the households and some trainers of trainers are 


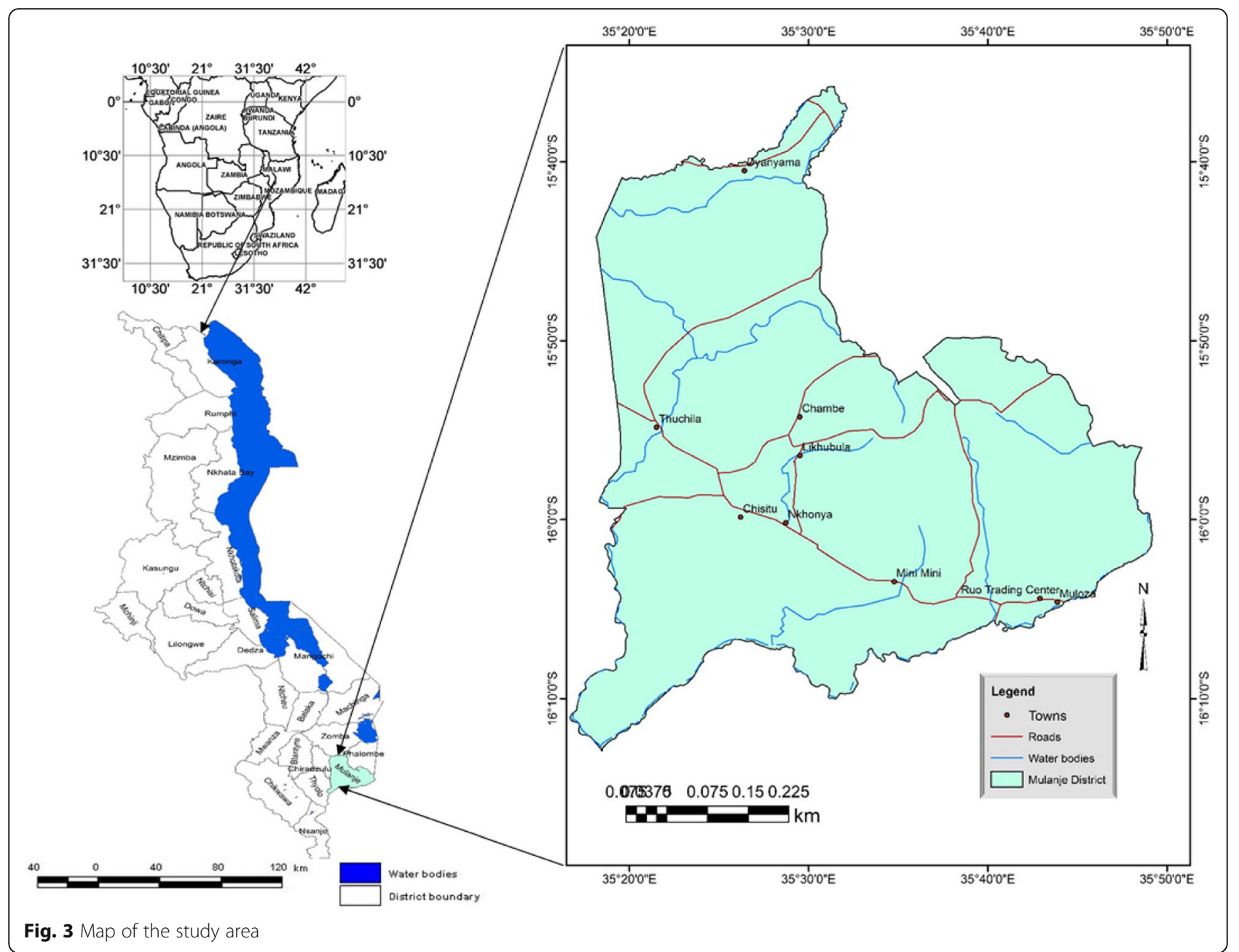

trained on how to use the stove. The training has to be continuous because tea estate workers are seasonal; whenever there are new occupants, they have to undergo the training process.

The study involved field experiments and administration of questionnaires to households that had Esperanza and 3-stone stoves only in their kitchens. Purposive sampling was used in selecting one tea estate out of the 15 in the Mulanje district. The Eldorado Tea Estate was chosen because it had a higher number of Esperanza stoves compared to other estates. Cluster sampling method was then used to sample two compounds from the estate (Mimosa chithando and Mpumula chithando) where the study was conducted. A cross-section study design was adopted in between two groups of households, one using a 3-stone stove and the other using the Esperanza stove. Using the cross-section design ensured that experiments were simultaneously carried out from both types of stoves [9].
Controlled cooking tests (CCTs) were conducted to compare the wood fuel saving of the Esperanza stove to the 3-stone stoves at GTZ-ProBEC laboratory and some selected households in Mulanje. The CCT measures the wood fuel consumption of stoves in controlled conditions. Field experiments were done using the Kitchen Performance Test (KPT) based on the Volunteer in Technical Assistance (VITA) protocol [13]. The KPT measures the relative rate of wood fuel consumed by each stove as they are used in the normal household environment. The KPT was conducted for four consecutive days. Each day involved recording the weight and moisture content of the wood fuel that the household presumably would use for cooking per day. After a day's cooking, the remaining wood fuel's weight and moisture content was also measured. If the remaining wood fuel was not sufficient for the next day, extra wood fuel was weighed, recorded, and added to the remaining wood fuel. The study was conducted on 21 Esperanza stoves and seventeen 3-stone stoves. 
All data were recorded on KPT Daily Data Forms during the study period. The data were then entered in the VITA KPT data calculation sheet for analysis.

In addition, an assessment of the effect of leaving the ash-removing hole open on the Esperanza stove was also conducted. The ash-removing hole runs from the combustion chamber to the outside of the stove. If left open, it allows heat to escape to the outside and cold air to flow into the combustion chamber. This assessment was done by recording temperatures using a thermocouple, whose probe was put at $5 \mathrm{~cm}$ from the outside surface of the stove into the ashremoving hole. The temperature was monitored for $60 \mathrm{~min}$ at 10 -min intervals from the time the fire was started for three consecutive days. The results were recorded and plotted on a graph.

\section{Results and discussion}

\section{Assessing usage of the Esperanza stove in days/week}

The results conducted on the Esperanza and 3-stone stoves in identified households in Mulanje district generated from the Kitchen Performance Tests (KPT) revealed that households were using both the Esperanza and the 3 -stone stoves. Figure 4 shows that the Esperanza stoves were used $100 \%$ of the time per day while the 3 -stone stove was used $25.8 \%$ of the time by the households. The 3 -stone stove was frequently used in the mornings to speed up activities to cater for people going to work and to school.

\section{Estimating wood fuel saving of the Esperanza stove}

Based on laboratory tests, the Esperanza stove has a $60 \%$ wood fuel saving compared to the 3-stone stoves (GTZProBEC: Rocket stoves and other technologies in Malawi, unpublished). However, the results from KPT revealed that the Esperanza stoves use more wood fuel than the 3-stone stoves (Table 1). The Esperanza stove used 147.5 MJ of energy per day while the 3-stove stone uses 78.3 $\mathrm{MJ}$ and energy use per capita of 29.8 for a 3 -stone stove while it

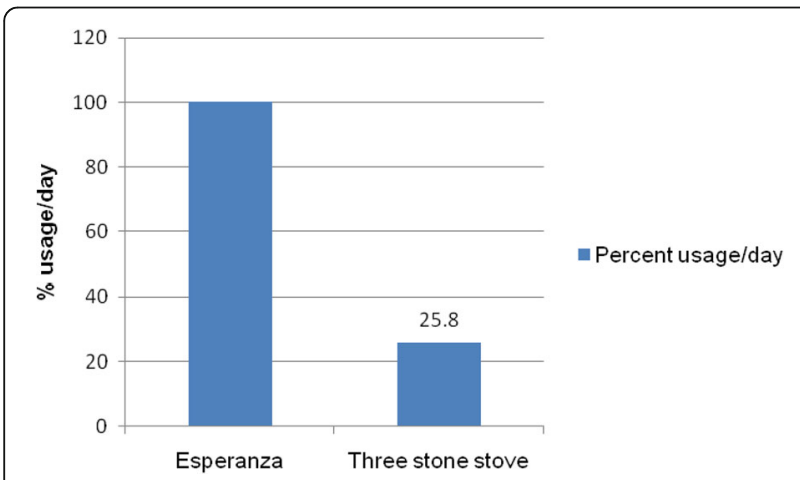

Fig. 4 Percentage usage per day of the Esperanza and 3-stone stoves was 54.5 for the Esperanza stove. Comparatively, the Esperanza stove is using about 65\% more energy and 24.7 MJ of energy per person than the 3-stone stove. These results are contrary to the findings by MacCarty et al. [14]; where in a laboratory comparison of five major types of biomass cooking stoves, it was found that an improved stove uses $2.47 \mathrm{MJ}$ to boil $1 \mathrm{~L}$ of water and then simmer it for $30 \mathrm{~min}$, while a basic 3-stone fire requires $6.55 \mathrm{MJ}$ to fulfill the same task. Though these tests were performed in the laboratory, they confirm the perception that 3-stone stoves use more energy than improved stoves $[2,9,15]$.

Comparing the performance of the Esperanza and the 3 -stone stoves revealed a marked difference in average fuel consumption per day as shown in Fig. 5 .

The 3-stone stoves had average wood fuel consumption of $4.2 \mathrm{~kg}$ with a standard deviation of 2.4 and a $95 \%$ confidence interval of 1.8 to 6.6. While the Esperanza stove had an average wood fuel consumption of $7.8 \mathrm{~kg}$ with a standard deviation of 2.3 and $95 \%$ confidence interval of 5.5 to 10.1 . This translates to about $86 \%$ increase in consumption of wood fuel when using the Esperanza stove compared to the 3-stone stove. Besides, the standard deviations showed that there were less variability in wood fuel consumption for the 3 -stone stove compared to the Esperanza. The more variable use of wood fuel in the Esperanza stove could be attributed to occupant turn-over and lack of training because of the seasonal nature of the estate activities. During the peak of tea-harvesting, new occupants come into the houses who could not have received training on the Esperanza stove. House ownership and structure contributes to increase in the adoption and proper use of new stove technologies [16]. Training provides knowledge about the particular tasks that are responsible for the greatest emissions and fuel consumption, and this can inform users to strategically use the ICS specifically for those tasks [16]. At the time of this study, the majority of the Esperanza users were new in the houses and were not home owners; they did not receive any training on the stove and did not understand the stove user guide. The new occupants require training, which however may not be available due to financial and personnel constraints, hence the inefficiency and high wood fuel consumption of the Esperanza stove. In addition, Namagembe et al. [17] noted that apart from stove user training, community-cooking demonstrations are another influential factor for correct and consistent use of an improved stove. The cooking demonstrations provide participants with the opportunity to observe and ask questions about the novelty of the stove technology. Most importantly, the demonstrations allow community members to witness the process of loading, lighting, and cooking on the improved cooking 
Table 1 Estimating daily average wood saving of the Esperanza and 3-stone stoves

\begin{tabular}{lllll}
\hline Stove type & Fuel use (kg) & $\begin{array}{l}\text { Fuel use/capita } \\
\text { (kg/person) }\end{array}$ & Energy use (MJ) & $\begin{array}{l}\text { Energy use/capita } \\
\text { (MJ/per) }\end{array}$ \\
\hline 3-stone & 4.2 & 2.1 & 78.3 & 29.8 \\
Esperanza & 7.8 & 2.9 & 147.5 & 54.5 \\
Saving & -6.1 & -0.8 & -69.2 & -24.7 \\
\hline
\end{tabular}

stove which could enhance wood fuel and energy efficiency. Some of the notable misuses in the study area included fire burning outside the stove, use of pots with smaller diameters than the stove's skirt leading to heat loss. Some heat losses were also observed when the Esperanza stove was used without closing the ashremoving hole. An example of fire burning outside the combustion chamber of the Esperanza stove is shown in Fig. 6.

Based on an adult equivalent (where adult equivalent is the amount of food prepared for a grown-up person per day), the Esperanza used an average of $3 \mathrm{~kg}$ of wood fuel compared to $1.5 \mathrm{~kg}$ used by the 3 -stone stoves. However, in a laboratory setting, the Esperanza was expected to consume $40 \%$ of the $1.5 \mathrm{~kg}$ of wood fuel used by the 3 -stone stove, which is approximately $0.6 \mathrm{~kg}$. At an adult equivalent of 1 , wood consumption for the Esperanza stove is $3 \mathrm{~kg}$ while an adult equivalent of 4.5 requires $12 \mathrm{~kg}$ of wood per day. For the 3 -stone stove, an adult equivalent of 1 consumes $2 \mathrm{~kg}$ per day while $4 \mathrm{~kg}$ corresponds to an adult equivalent of 4.5. The adult equivalent takes into account the food that is taken/ eaten by a grown-up person based on the VITA KPT calculation. Thus, it is a tool that estimates real food consumption of family members with distinct energy needs [18]. Figure 7 shows that the number of adult equivalent has an impact on the wood fuel used per day.
It shows that as the number of adult equivalent increases, the daily wood fuel use also increases for both cooking technologies.

Moisture affects the burn rate for wood and when moisture content is high, it can affect the ability of the wood to ignite. Equilibrium moisture content of wood can vary from 1 to $25 \%$ in ambient temperature and humidity conditions [19]. In 1987, Smith [20] discovered that moisture has a complex interaction with the two components of stove efficiency, namely combustion efficiency and heat transfer efficiency. Measurements of moisture content in the KPT were used to estimate the dry fuel content of the wood as the moisture content contributes significantly to mass. Wood fuel consumption of the Esperanza and 3-stone stoves was compared between wet wood and dry wood. Figure 8 shows a comparison of the consumption of dry wood in kilograms for the Esperanza with the 3-stone stoves.

The results in Fig. 8 indicate that the Esperanza stove used more dry wood than the 3-stone stove. Wet wood consumption at an adult equivalent of 2.3 shows high consumption of the Esperanza stove $(9.4 \mathrm{~kg})$ compared to the 3 -stone stove $(4.4 \mathrm{~kg})$. These results agree with the results that were found in Guatemala; wherein standard water boiling and cooking tests, unimproved plancha consumed more fuel and took longer than the

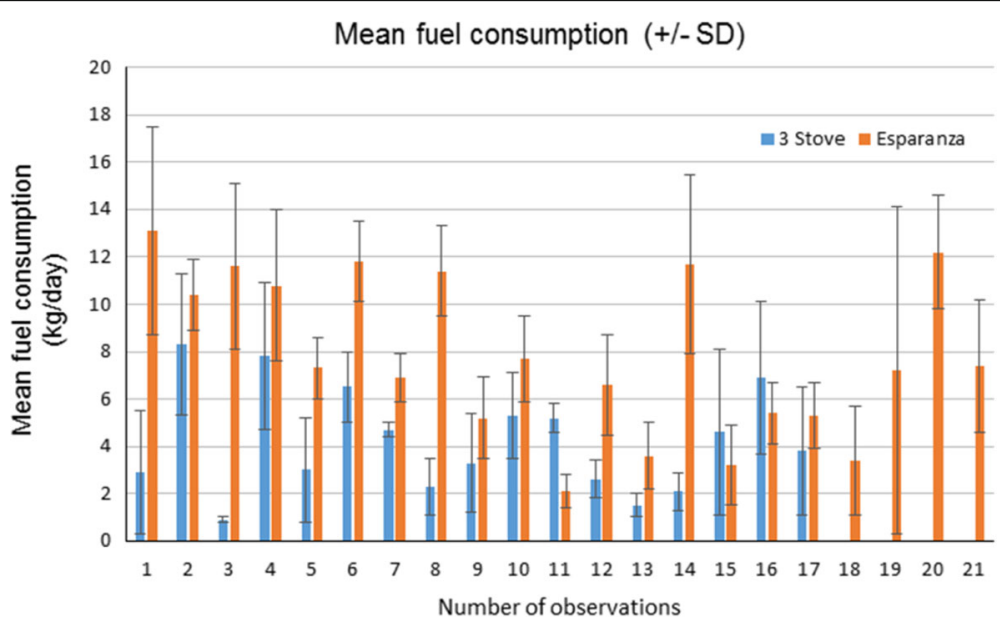

Fig. 5 Comparison error bars showing 95\% Cl between the Esperanza and 3-stone stoves 


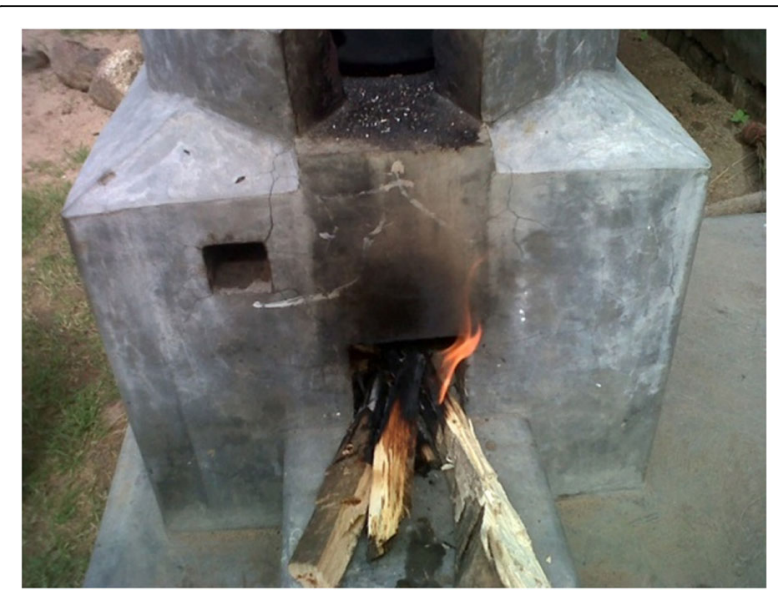

Fig. 6 The Esperanza stove in use with combustion outside the stove

open fire. Smith [20] showed that improving baffle design of the plancha increased thermal efficiency of the plancha by $12 \%$ [11].

There is a difference in results obtained from the CCT and the KPT from this study. When conducting the CCT, all conditions and rules of the stove are followed whereby wood fuel is not allowed to burn outside the combustion chamber and the ash-removing hole is always closed. For maximum efficiency of the Esperanza stove, the ashremoving hole has to be closed throughout the cooking period. In this study, it was observed that almost all the users were using the stove without closing the ash hole which could have negative implications on wood fuel consumption and energy saving of the Esperanza stove. Hence, a thermocouple was used to monitor temperature from the ash-removing hole (Fig. 9). The average results of the observations are plotted in Fig. 10.

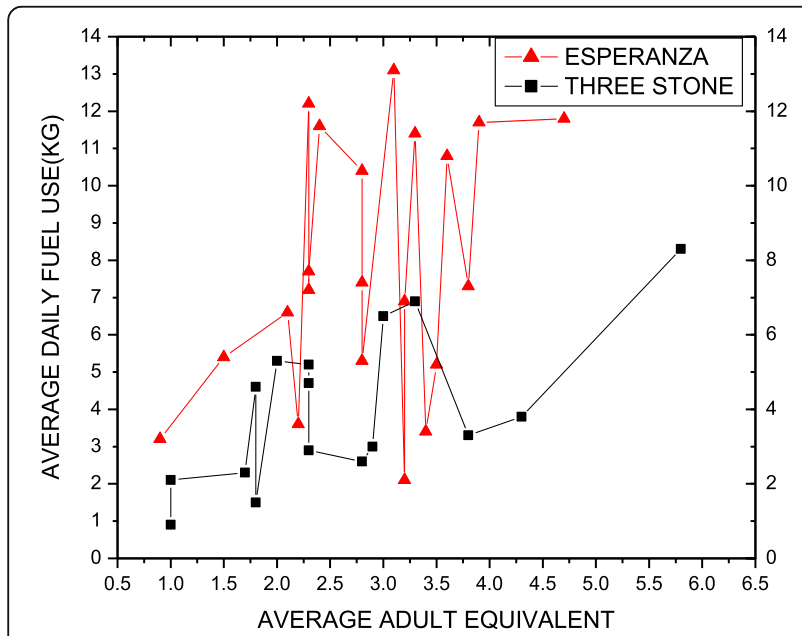

Fig. 7 Average daily wood fuel use for the Esperanza and 3-stone stoves

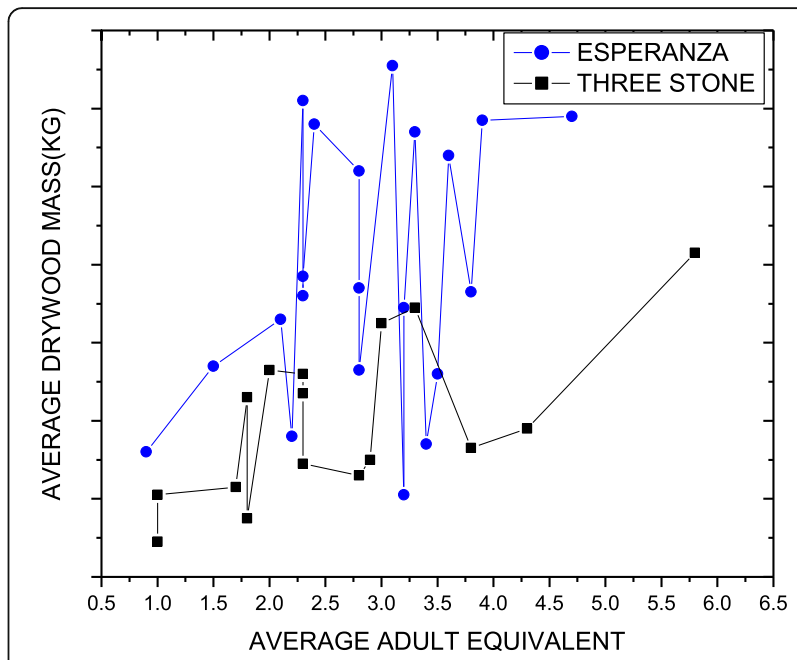

Fig. 8 Comparison of adult equivalent average dry wood consumption between the Esperanza stove and 3-stone stove

The result in Fig. 10 shows that temperature increased with time. For instance, at time 0 , the temperature was $>30{ }^{\circ} \mathrm{C}$ and at $60 \mathrm{~min}$ it had increased to $40{ }^{\circ} \mathrm{C}$, recording an increase of $10{ }^{\circ} \mathrm{C}$ within an hour. These findings confirm that a lot of heat is lost during cooking if the ash-removing hole is open, resulting in high wood fuel consumption and low thermal efficiency per cooking session. In a 3-stone stove, 85 to $90 \%$ of the energy content in the wood is lost as heat to the environment outside the cooking pot [14, 21]. When users of the Esperanza perpetuate 3-stone practices, energy saving potentials with improved cooking stoves are far smaller and less cost-efficient. This low efficiency not only wastes natural resources, but also boosts air pollution and greenhouse gas emissions because of incomplete combustion [22]. Hence, the need to keep the hole closed so that heat is kept inside the combustion chamber of the

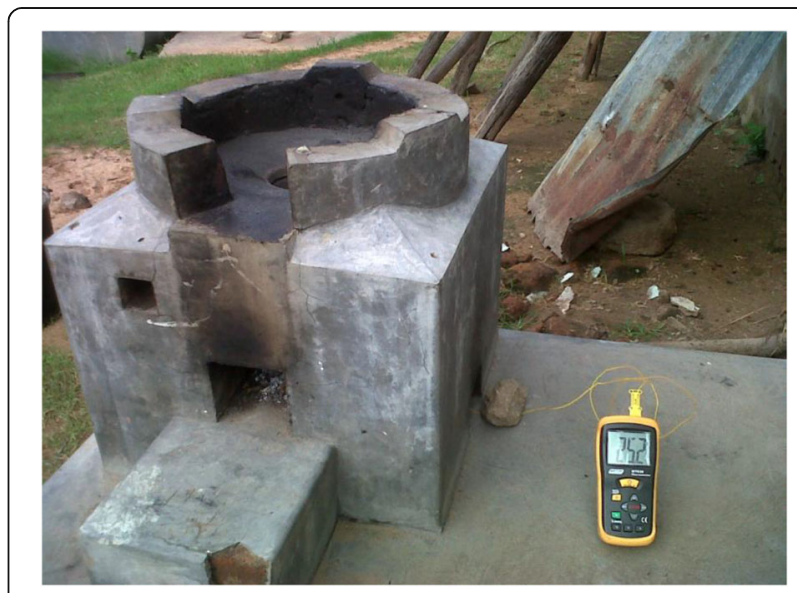

Fig. 9 Setup for temperature monitoring on the ash-removing hole of the Esperanza stove 


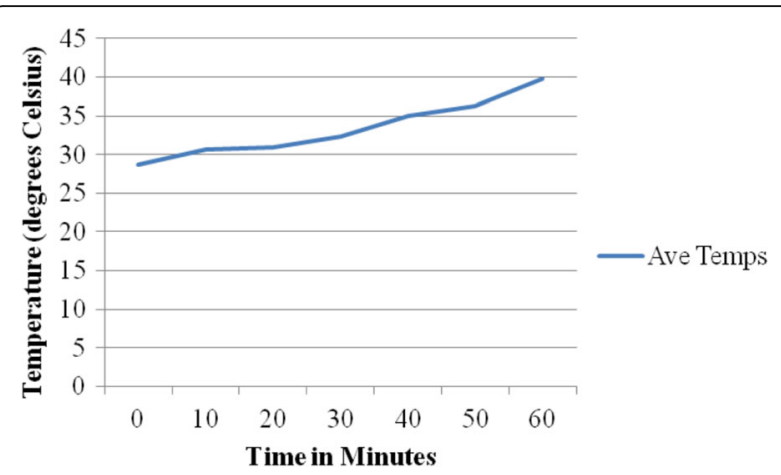

Fig. 10 Temperature variation with time at the ash-removing hole

stove is imperative. This is important because high temperatures are required in a stove for complete combustion and for increased stove efficiency.

\section{Conclusions}

Three-stone stoves are still the preferred mode of cooking technology in most rural and peri-urban environments in Malawi. Despite the reported wood fuel saving of $60 \%$ of the Esperanza stove compared to the 3-stone stove in a laboratory controlled condition test; the results of this study in a typical domestic setting showed high wood fuel consumption. This was attributed to home occupant turn-over and lack of training to new users. The cooking practices inherent for the 3-stone stove increases heat loss and wood fuel consumption such that if the users of the Esperanza stove (or any other improved cookstove) are not trained, the improved stoves will still be less efficient. The shift to the improved stove technologies therefore requires an integration of the users' experiences and expectations to ensure proper use of these technologies that save energy and the environment. Thus, the importance of training on the proper use of the Esperanza stove is recommended in order to optimize its performance and maximize energy saving. There is also a need to carry out studies on the ideal type of wood fuel that is suitable for use in the Esperanza stove.

Although the KPT is difficult to control, leading to data with high variance, it has the advantage of reflecting the true fuel consumption in study households as they proceed with their everyday cooking activities. Laboratory-based investigations such as the water boiling test (WBT) can be employed as a screening procedure to identify inefficient stove designs prior to dissemination and adoption. Such results should not be relied upon as the only method of efficiency assessment but it is worthwhile to consider changes in the KPT protocol that could be adopted to generate more significant results.

\section{Limitations}

The study was conducted in an area where most of the users did not have knowledge on how to use the Esperanza stove as they did not have any training. For future study, there is need to have a set of trained users of the Esperanza stove using it in the typical domestic setting for the results to be used as a benchmark or a model performance of the Esperanza stove.

\section{Acknowledgements}

The study was possible through financial assistance from the Malawi Environmental Endowment Trust (MEET). Most importantly, we thank the residents of the Eldorado Tea Estate who participated in this study. The authors would like to thank the Mulanje Renewable Energy Agency (MuREA) for the use of their measuring equipment and the anonymous reviewers for their inspiring and constructive comments on the paper.

\section{Authors' contributions}

MFLC is the lead author and made a substantial contribution to the conception and design of the manuscript; MFLC also drafted the article. CK administered the VITA questionnaire to households within the study area and also analyzed the data. JM contributed to the field work, specifically the efficiency testing of stoves and analyzing the results. CM designed the experiment that was used for testing the heat losses from a cleaning hole on the improved cooking stove. LGP critically revised the manuscript for important intellectual content. She also formatted the paper to conform to the specifications of the journal. All authors read and approved the final manuscript.

\section{Competing interests}

The authors declare that there are no financial or personal relationships which may have inappropriately influenced them in writing this article.

\section{Publisher's Note}

Springer Nature remains neutral with regard to jurisdictional claims in published maps and institutional affiliations.

\section{Author details}

${ }^{1}$ North-West University, Mafikeng Campus, Mahikeng, North West Province, South Africa. ${ }^{2}$ Physics Department, Chancellor College, University of Malawi, Zomba, Malawi.

Received: 24 October 2016 Accepted: 8 June 2017

Published online: 03 July 2017

\section{References}

1. WRI (1998) World Resources Database 1998-99. (On diskette). WRI, Washington

2. Malawi Government (2003) National energy policy for Malawi. Malawi Government, Lilongwe

3. Kambewa P, Mataya B, Sichinga WK, Johnson T (2007) Charcoal-the reality: charcoal consumption, trade and production in Malawi. Technical report to the Forest Governance Learning Group. Malawi COMPASSII, Blantyre

4. WHO (1992) Indoor air pollution from biomass fuel. WHO, Geneva

5. Still D (2005) Design principles for wood burning cook stoves. Aprovecho Research Centre, Partnership for Clean Indoor Air, Shell Foundation, Oregon

6. Robles-Gil S (2001) Climate information for biomass energy applications. (Report on solar energy Commission for Climatology). World Metrological Organisation, La Paz

7. Malawi HEDON (2013) Households energy network. Improved cookstoves in Malawi., http://www.hedon.info/goto.php/ImprovedCookstovesInMalawi. Accessed on $15 \mathrm{Nov}$

8. Taulo JL, Mkandawire RW, Gondwe KJ (2008) Energy policy research baseline study for Mulanje and Phalombe districts. Malawi Industrial Research and Technology Development Centre, Blantyre

9. Bailis R, Berrueta V, Chengappa C, Dutta K, Edwards R, Masera O, Still D, Smith K (2007) Performance testing for monitoring improved biomass stove interventions: experiences of the household energy and health project. Energy Sustain Dev 11(2):57-70 
10. Jetter J, Zhao Y, Smith KR, Khan B, Yelverton T, DeCarlo P, Hays MD (2012) "Pollutant emissions and energy efficiency under controlled conditions for household biomass cookstove and implications for metrics useful in setting international test standards. Environ Sci Technol 46(19):10827-10834

11. Granderson J, Sandhu JS (2005) Kitchen performance tests and focus group impressions of improved woodburning cookstoves in the Guatemalan highlands. (Maxwell Student Projects, Max-05-01). School of Public Health, University of California, Berkeley

12. NSO (2008) 2008 Population and Housing Census Preliminary Report. Zomba, National Statistical Office

13. VITA (1985) Testing the efficiency of wood-burning cookstoves: provisional international standards. Volunteers in Technical Assistance, Arlington

14. MacCarty N, Ogle D, Still D, Bond T, Roden C (2008) A laboratory comparison of the global warming impact of five major types of biomass cooking stoves. Energy Sustain Dev 12(2):56-65

15. Philips (2006) "Philips develops a woodstove that saves lives and preserves energy resources", Philips Research press release, February 2., http://www. research.philips.com/newscenter/archive/2006/060227-woodstove.html. Accessed on 05 March 2017

16. Puzzolo E, Stanistreet D, Pope D, Bruce N, Rehfuess E (2013) Factors influencing the large scale uptake by households of cleaner and more efficient household energy technologies.". EPPI Centre, London

17. Namagembe A, Muller N, Scot LM, Zwisler G, Johnson M, Arney J, Charron D, Mugisha E (2015) "Factors influencing the acquisition and correct and consistent use of the top-lit updraft cookstove in Uganda.". J Health Commun 20(sup 1):76-83

18. Claro RM, Levy RB, Bandoni DH, Mondini L (2010) Per capita versus adultequivalent estimates of calorie availability in household budget surveys, Cad. Saúde Pública, Rio de Janeiro 26(11):2188-2195

19. L'Orange C, DeFoort M, Willson B (2012) Influence of testing parameters on biomass stove performance and development of an improved testing protocol. Energy Sustain Dev 16(1):3-12

20. Smith K (1987) Biofuels, air pollution and health: a global review. Plenum Press, New York

21. Adria, O., J. Bethge, S. T. WI, A. D. WI, H. Volkmer and S. Salow (2013) "What users can save with energy-efficient cooking stoves and ovens", Wuppertal Institute for Climate, Environment and Energy. Accessed 13 March 2017

22. Shankar A, Johnson M, Kay E et al (2014) Maximizing the benefits of improved cookstoves: moving from acquisition to correct and consistent use. Global Health: Science and Practice 2(3):268-274

\section{Submit your manuscript to a SpringerOpen ${ }^{\circ}$ journal and benefit from:}

- Convenient online submission

- Rigorous peer review

- Open access: articles freely available online

- High visibility within the field

- Retaining the copyright to your article 